\title{
A Incorporação da Dimensão Integrativa nos Processos de Ava- liação do Desempenho Organizacional: Um Estudo de Caso
}

\author{
The Incorporation of the Integrative Dimension to the Organizational Performance Assess- \\ ment Processes: A Case Study
}

\section{Ademar Dutra}

Doutorado em Engenharia de Produção na Universidade Federal de Santa Catarina

Professor do Programa de Pós-Graduação em Administração da Universidade do Sul de Santa Catarina

Endereço: Rua Trajano, n॰ 119 - Centro

CEP: 88010-010 - Florianópolis/SC - Brasil

E-mail: ademar.dutra@unisul.br

Telefone: (48) 9972-4069

\section{Sandra Rolim Ensslin}

Doutorado em Engenharia de Produção na Universidade Federal de Santa Catarina

Professora do Programa de Pós-Graduação em Contabilidade e Engenharia de Produção da Universidade Federal de Santa Catarina

Endereço: Rua Itararé, n॰ 41 - Parque São Jorge - Itacorubi

CEP: 88034-470 - Florianópolis/SC - Brasil

E-mail: sensslin@gmail.br

Telefone: (48) 3721-6662

\section{Leonardo Ensslin}

Ph.D. em Engenharia Industrial e Sistemas na University of Southern California

Professor do Programa de Pós-Graduação em Contabilidade e Engenharia de Produção da Universidade Federal de Santa Catarina

Endereço: Rua Frei Caneca, n॰ 629 - apt 402 - Centro

CEP: 88025-000 - Florianópolis/SC - Brasil

E-mail: leonardoensslin@gmail.com

Telefone: (48) 3721-7022

\section{Marcus Vinícius Andrade de Lima}

Doutorado em Engenharia de Produção na Universidade Federal de Santa Catarina

Professor do Programa de Pós-Graduação em Administração da Universidade do Sul de Santa Catarina

Endereço: Rua Trajano, n॰ 119 - Centro

CEP: 88010-010 - Florianópolis/SC - Brasil

E-mail: marcus.lima@unisul.br

Telefone: (48) 9971-8979

Artigo recebido em fevereiro de 2009. Passou por uma avaliação double blind review em agosto de 2009. Aceito em novembro de 2009 pela Editora Científica Sandra Rolim Ensslin. Artigo apresentado no II Encontro de Administração da Informação (EnADI), 2009, Recife, 2009. 


\title{
$\overline{\text { Resumo }}$
}

Este artigo, de caráter exploratório, visa apresentar uma proposta metodológica que permite incorporar a dimensão integrativa nos processos de Avaliação do Desempenho Organizacional, por meio da Metodologia Multicritério de Apoio à Decisão Construtivista. A dimensão integrativa busca identificar as variáveis internas de desempenho de cada subsistema organizacional e aquelas decorrentes das interrelações e interconexões entre os diversos subsistemas. Argumenta-se que a proposta, operacionalizada em um estudo de caso, conseguiu cumprir a tarefa de: (i) identificar as variáveis em que um subsistema afeta e é afetado pelo desempenho de outro subsistema; (ii) identificar as estratégias mais adequadas para melhorar o desempenho do sistema como um todo; e (iii) permitir que cada subsistema, na medida em que se depare com duas alternativas capazes de aperfeiçoar seu desempenho, opte pela alternativa que apresentar maior contribuição para o desempenho global do sistema.

Palavras-chave: Avaliação do Desempenho Organizacional, Metodologia Multicritério de Apoio à Decisão Construtivista (MCDA/C), Dimensão Integrativa, Sistema Organizacional, Subsistema Organizacional.

\begin{abstract}
This exploratory paper aims to present a methodological proposal that allows incorporating the integrative dimension to the Organizational Performance Assessment processes by using the Constructivist Multi-criteria Decision Aid Methodology. The goal of the integrative dimension is to identify the internal performance variables of each organizational subsystem and those deriving from interrelations and interconnections among the various subsystems. It is argued that this proposal, which was operationalized in a case study, managed to: (i) identify the variables in which a subsystem affects and is affected by the performance of another subsystem; (ii) identify the most suitable strategies to improve the performance of the system as a whole; and (iii) allow for each subsystem to choose the alternative that contributes the most to the global performance of the system when faced with alternatives that may lead to performance improvement.
\end{abstract}

Key words: Organizational Performance Assessment, Constructivist Multi-Criteria Decision Aid Methodology (MCDA/C), Integrative Dimension, Organizational System, Organizational Subsystem.

\section{Introdução}

A importância do processo de Avaliação do Desempenho Organizacional pode ser caracterizada por meio da afirmação: "Tudo o que não é medido não é gerenciado" (KAPLAN, NORTON, 1997, p. 21). Assim, ter um processo para avaliação do desempenho de suas estruturas de trabalho e atividades propicia um diferencial competitivo às organizações. Considerando, ainda, que a melhoria do desempenho organizacional passou a ser o foco diário de todos os profissionais que exercem funções de liderança, a adoção de sistemas de avaliação torna-se indispensável nos dias atuais.

Historicamente, os processos de avaliação de desempenho organizacional têm passado por transformações significativas, tendo em vista o ajuste e o alinhamento a novos modelos de organização e gestão que têm disciplinado a dinâmica de funcionamento do mundo organizacional (DUTRA, 2003; BORTOLUZZI, 
VICENTE, ENSSLIN. S, ENSSLIN, 2009).

No contexto organizacional contemporâneo, a busca por competitividade tem exigido das organizações preocupações permanentes com sistemas de avaliação de seu próprio desempenho. Nesse sentido, verifica-se, na literatura, as propostas de incorporação da dimensão sistêmica (SANNEMANN, 2001) que reconhece que um dado subsistema é influenciado pelo meio externo - e da dimensão sinergética (ENSSLIN.S, 2002) - que propõe formas de possibilitar a um dado subsistema " $A$ " enxergar e interagir com os outros subsistemas, ao gerenciar o seu próprio sistema". Os autores da presente pesquisa acreditam que a incorporação da dimensão integrativa ao processo de avaliação de desempenho realizado nessas bases (sistêmico-sinergético) pode potencializar o conhecimento já gerado e propiciar um equilíbrio dinâmico e global pelo olhar conjunto dos subsistemas, a si próprio e aos outros, identificando as estratégias mais apropriadas para o sistema como um todo.

A dimensão integrativa, no contexto da Avaliação de Desempenho Organizacional (ADO), busca identificar as variáveis internas de desempenho de cada subsistema e, sobretudo, as decorrentes das interrelações e interconexões entre os diversos subsistemas, enfatizando a escolha das estratégias mais relevantes para a melhoria do sistema como um todo (DUTRA, 2003). O contexto de aplicação da dimensão é o ambiente organizacional, caracterizado por sistema e subsistemas, podendo, ainda, apresentar outros desdobramentos, de acordo com a estrutura da organização ou de seus processos de trabalho.

Nesse cenário, surge a pergunta da pesquisa que orienta o trabalho: Como incorporar a dimensão integrativa nos processos de avaliação de desempenho organizacional? Com vistas à responder à pergunta de pesquisa proposta pelos autores, o objetivo do presente trabalho consiste em apresentar uma proposta metodológica que permita incorporar a dimensão integrativa nos processos de avaliação do desempenho organizacional e construir um modelo de ADO para uma empresa área de telecomunicações. Observe-se que para a finalidade de preservar a identidade da organização, esta será denominada no trabalho por "uma empresa da área de telecomunicações".

Para dar conta do objetivo estabelecido, selecionou-se como instrumento de intervenção a Metodologia de Multicritério de Apoio à Decisão - Construtivista (MCDA-C), por esta ter sido a base da operacionalização das dimensões sistêmica e sinergética das abordagens de ADO propostas anteriormente.

No contexto de aplicação no âmbito organizacional, a presente pesquisa demonstra-se relevante ao propor uma metodologia capaz de capturar dimensões externas e seus reflexos, capacidade essa não contemplada em métodos tradicionais de avaliação de desempenho. Assim, a relevância prática fica evidenciada, à medida que a metodologia proposta se preocupa em: (i) extrair do decisor 
os aspectos considerados relevantes para fins de avaliação do desempenho, no contexto interno de seu subsistema e no contexto das interrelações; (ii) mensurar esses aspectos, em termos de uma escala; e, (iii) integrar todos esses aspectos, de forma a possibilitar uma visão global do sistema de avaliação. Assim, esta pesquisa pretende oferecer uma contribuição metodológica para aprimorar modelos de Avaliação de Desempenho Organizacional que atendam às demandas do contexto organizacional da atualidade.

O presente artigo está assim organizado: após esta primeira seção de caráter introdutório, a seção 2 - Metodologia da Pesquisa - é dividida em duas partes, que apresentam, respectivamente, o enquadramento metodológico e a Metodologia MCDA-C, capaz de promover a incorporação da dimensão integrativa em seu processo de avaliação do desempenho organizacional. A seção 3 - Referencial Teórico - apresenta os eixos que norteiam a pesquisa: Avaliação de Desempenho Organizacional (ADO), informando a afiliação teórica adotada nesta pesquisa, e a Dimensão Integrativa. A seção 4 - Resultados - apresenta a operacionalização da proposta metodológica para a construção de um modelo de Avaliação de Desempenho Organizacional (ADO) que incorpore a dimensão integrativa em uma empresa área de telecomunicações. A seção 5 - Considerações Finais - tece reflexões sobre a proposta aqui apresentada, com base no modelo construído, e faz recomendações para futuras pesquisas a partir das limitações deste estudo. Finalmente, a seção 6 - Referências Bibliográficas - apresenta a bibliografia utilizada na pesquisa.

\section{Metodologia da Pesquisa}

A metodologia da pesquisa utilizada no artigo divide-se em duas partes. A primeira parte dedica-se ao enquadramento metodológico da pesquisa. A segunda parte apresenta as premissas do instrumento de intervenção selecionado.

\subsection{Enquadramento metodológico}

A presente pesquisa possui caráter exploratório (RICHARDSON, 2008) e se constitui em um estudo de caso (YIN, 2005), uma vez que os autores buscam analisar, com profundidade, um objeto específico: uma empresa da área de telecomunicações. O caráter exploratório é confirmado pelo objetivo geral que visa construir um modelo de Avaliação de Desempenho Organizacional da empresa, incluindo a dimensão integrativa, por meio da operacionalização da metodologia MCDA-C; da identificação das variáveis em que um subsistema afeta e é afetado pelo desempenho de outro subsistema; da identificação das estratégias mais adequadas para melhorar o desempenho do sistema como um todo; e da possibilidade 
de permitir que cada subsistema, na medida em que se depare com duas alternativas capazes de aperfeiçoar seu desempenho, opte pela alternativa que apresentar melhor contribuição para o desempenho global do sistema.

No que diz respeito à natureza do artigo, esta pesquisa é classificada como estudo de caso, uma vez que investiga em profundidade o desempenho organizacional da empresa da área de telecomunicações.

No que tange à construção do modelo, a fonte de coleta dos dados é de natureza primária e secundária, pelo fato de os dados terem sido coletados diretamente com o gestor da empresa da área de telecomunicações, durante reuniões, conduzidas por meio de técnicas de brainstorming e entrevistas, e junto ao referencial teórico para subsidiar as decisões do gestor, quando necessário.

A abordagem metodológica utilizada classifica-se como qualitativoquantitativa (RICHARDSON, 2008). A abordagem quantitativa se faz presente na conversão do modelo qualitativo em quantitativo por meio do software Measuring Attactiveness by a Categorical Based Evaluation Technique (MACBETH) e Excel, quando da utilização do método de agregação aditiva e da análise de agregação de valor promovida pela proposta de intervenção, para a alavancagem do desempenho global do sistema (empresa da área de telecomunicações). A abordagem qualitativa se faz presente no processo de identificação e representação das variáveis que irão responder pelo desempenho do sistema, bem como da identificação da possibilidade de desempenho dessas variáveis.

Como instrumento de intervenção para a construção do modelo, a ferramenta selecionada foi a metodologia Multicritério de Apoio à Decisão Construtivista (MCDA-C), cujas premissas são apresentadas na subseção a seguir.

\subsection{A Metodologia Multicritério de Apoio à Decisão - Construtivista (MCDA-C) como instrumento de intervenção}

A MCDA-C se constitui em uma ferramenta de apoio à tomada de decisão em um contexto multicritério, cujas premissas podem ser sumarizadas conforme segue: (i) consenso em relação ao fato de que, nos problemas decisórios, existem múltiplos critérios; (ii) consenso em relação ao fato de que, em substituição à noção de melhor solução, propõe-se a busca por uma solução que melhor se enquadre nas necessidades do decisor e no contexto decisional como um todo.

Nesse contexto, com base em Bana e Costa (1988, 1993), Bana e Costa e Vincke (1990), e Roy (1993), destacam-se como características da MCDA-C: (i) o reconhecimento dos limites da objetividade e a consequente aceitação da subjetividade; (ii) a incorporação da dimensão construtivista, segundo a qual ocorre aprendizagem constante e evolutiva do contexto decisório, em oposição à crença em um conjunto de ferramentas para permitir uma solução única e melhorada do 
problema (convicção do construtivismo calcada na noção de participação, conduzindo a um novo paradigma de aprendizagem); (iii) a aceitação da inseparabilidade dos elementos de natureza objetiva e dos elementos de natureza subjetiva (convicção da interpenetração em consonância com o aspecto de indivisibilidade do sistema); (iv) a proposta de uma atividade de apoio à decisão, o diferencial central da MCDA-C frente a outras metodologias; (v) a presença deste apoio em todas as etapas do processo decisório (estruturação, avaliação e recomendação); e (vi) a incorporação de uma linguagem que é, ao mesmo tempo, linear (fazendo uso da linguagem humana natural) e não linear (fazendo uso de representações visuais, que permitem a simultaneidade da informação).

Ainda, no que se refere à atividade de apoio à decisão, Bana e Costa (1995a, p. 1) afirmam que essa atividade pode ser vista como um processo de interação com uma situação problemática "mal estruturada", na qual os elementos e as suas relações emergem de forma mais ou menos caótica.

Já para Roy (1993), a atividade de apoio à decisão é definida como a atividade em que um facilitador, utilizando-se de procedimentos científicos, ajuda a obter elementos de resposta a questões perguntadas aos atores envolvidos em um processo decisório, elementos estes que ajudam a tornar clara esta decisão com a finalidade de fornecer aos atores as mais favoráveis condições possíveis para o tipo de comportamento que aumentará a coerência entre a evolução do processo de um lado, e as metas e/ou sistemas de valores em que esses atores operam, por outro lado (ROY, 1993).

Denis Bouyssou (apud BANA e COSTA; VINCKE, 1990) sintetiza seus pensamentos a respeito da atividade de apoio à decisão da seguinte forma: "Apoio à decisão consiste em tentar fornecer respostas a perguntas levantadas por atores envolvidos em um processo decisório usando um modelo claramente especificado".

Diante das definições apresentadas acima, pode-se dizer que: (a) a MCDA-C tem como objetivo central possibilitar, aos indivíduos envolvidos em um processo decisório, o aumento do seu grau de conformidade e de entendimento entre a evolução de um processo de tomada de decisão, na presença de seus sistemas de valor e objetivos (pontos de vista); (b) a metodologia inclui o papel do facilitador no processo de ajuda à decisão; e (c) sua preocupação central é encontrar a solução de melhor compromisso segundo a percepção e valores dos decisores.

Outro ponto a ser salientado é o fato de que a atividade de apoio à decisão não vem para substituir à tomada de decisão em si; ambas são atitudes diferentes e fundamentais nesse contexto. $\mathrm{O}$ apoio à decisão, desempenhado pela pessoa do facilitador, não pode ser visto como uma atitude restrita ao favorecimento do entendimento de um problema. Pelo contrário, para conseguir possibilitar o 
entendimento do problema, essa atitude necessita identificar alguns aspectos, frequentemente caracterizados pela dificuldade de evidenciamento, a saber: (a) a identificação do conjunto de ações potenciais (e da indefinição de suas fronteiras); (b) a construção dos critérios; e (c) a modelação das preferências. Em outras palavras, a atividade de apoio à decisão tem como objetivo fornecer as informações sobre as questões que vão surgindo e orientar e apoiar o decisor com relação àquelas que mais atendem às suas expectativas para que tome decisões mais informadas, fundamentadas e claras sobre um determinado problema. A tomada de decisão se reveste de uma enorme subjetividade, por ser avaliada segundo os juízos de valor do decisor, a quem compete escolher e decidir.

Nesse contexto, conclui-se que a atividade de apoio à decisão se faz fundamentalmente presente em todas as etapas do processo decisório, conforme a Figura 1. Na fase de estruturação, essa atividade se insere no processo visando à 'construção' de uma estrutura consensualmente aceita pelos atores.

Figura 1: Processo Decisório sob a perspectiva da MCDA-C

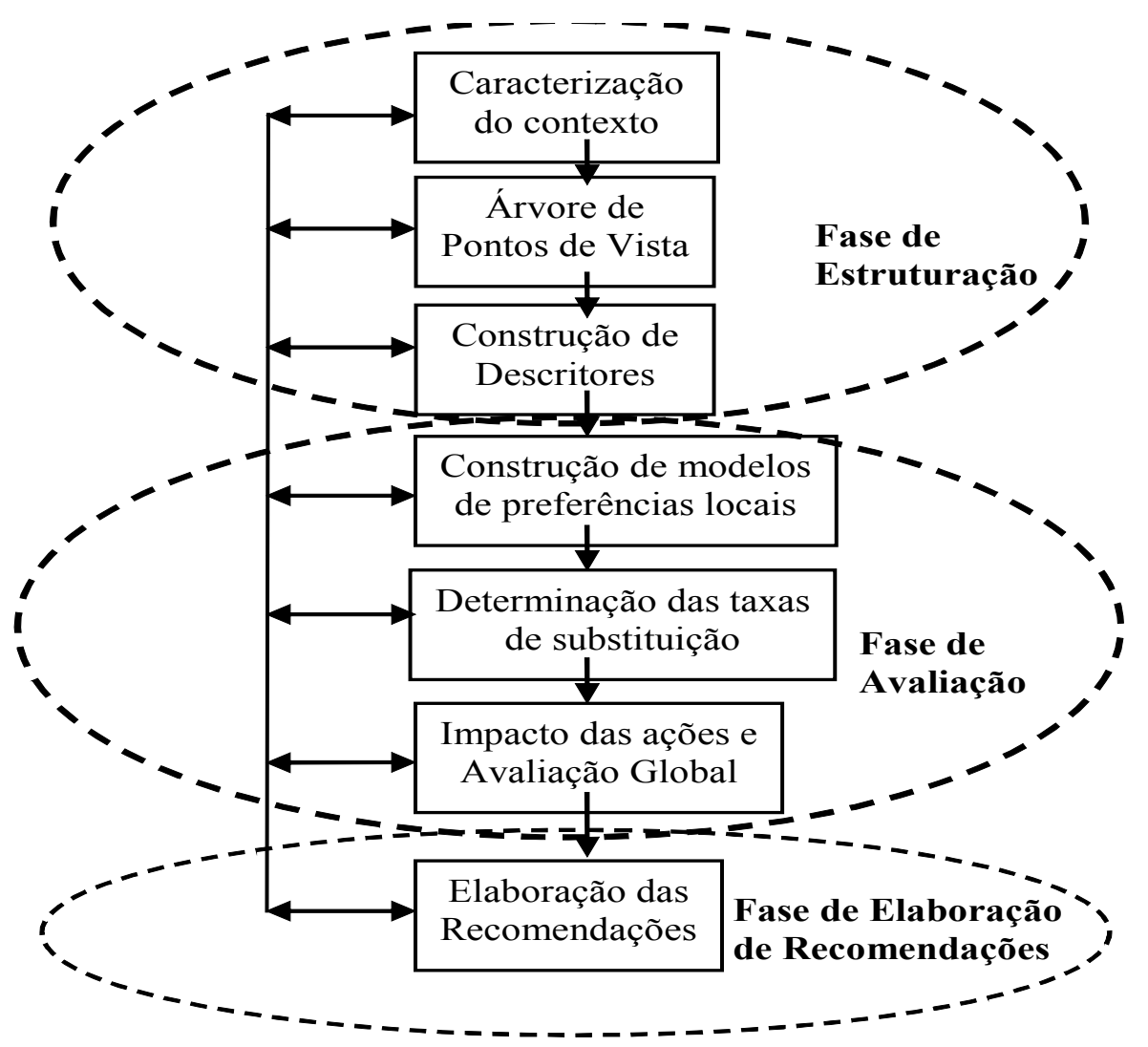

Fonte: Dutra, Ensslin, Ensslin, S. (2000).

Verifica-se, então, que ela não procura modelar uma realidade preexistente, muito pelo contrário. Na fase de avaliação, a atividade de apoio, seguindo uma conduta de interação e aprendizagem, sendo, consequentemente, construtivista, desenvolve um modelo no qual as ações potenciais serão avaliadas. Sendo assim, a atividade de apoio não procura seguir um caminho normativo, nem busca a so- 
lução ótima. Na fase de recomendação, essa atividade procura fornecer subsídios aos decisores, por meio de algumas ferramentas, para que estes tenham condições de analisar a estratégia mais adequada a ser adotada em cada cenário específico. A seguir, a Figura 1 apresenta as fases do processo decisório sob a perspectiva da MCDA-C.

Diante da visualização permitida pela figura acima, e considerando-se o fato de que a atividade de apoio é feita de forma contínua e interativa, apresentando-se, portanto, como dinâmica e recursiva, pode-se concluir que o processo de tomada de decisão não é linear e sequencial. Ou seja, a maneira de conduzir esse processo deve ser cíclica e dinâmica. Essas características de condução - cíclica e dinâmica - são indicadas, na Figura 1 pelas setas de todas as etapas cruciais e pelas sobreposições das elipses, entre as três fases fundamentais.

Nesse sentido, dois aspectos devem ser salientados: (a) o processo de tomada de decisão se caracteriza pela possibilidade de recursividade total, o que não significa, porém, que se pode inverter a ordem de realização das etapas; (b) a elaboração das recomendações, que além de se constituir como uma fase específica, também se constitui, ao término do processo de tomada de decisão, como uma etapa interveniente (inserida) em todas as demais, uma vez que o facilitador se faz presente em todos os momentos.

Para cumprir sua função, a metodologia MCDA-C faz uso de três fases diferenciadas, mas correlacionadas: (i) a estruturação do contexto decisório; (ii) a construção de um modelo de avaliação de alternativas/ações; e, (iii) a formulação de recomendações visando ações de aperfeiçoamento.

\section{Referencial Teórico}

Nesta seção, apresentam-se, de forma sucinta, os eixos que informam a pesquisa: a afiliação teórica de Avaliação de Desempenho Organizacional (ADO) e a Proposta da Dimensão Integrativa.

\subsection{Afiliação Teórica de Avaliação de Desempenho Organizacional adotada nesta pesquisa}

Os autores da presente pesquisa argumentam sobre a importância da necessidade do estabelecimento da afiliação teórica de Avaliação de Desempenho Organizacional (ADO) que informa a presente pesquisa, uma vez que optaram pela não apresentação e discussão dos diversos conceitos e noções que existem na literatura publicada pertinente. Sendo assim, a partir do estabelecimento dessa afiliação teórica, os leitores deverão refletir sobre a proposta aqui formulada a partir desta afiliação. 
Nesse contexto, este trabalho afilia-se ao conceito de Avaliação de Desempenho Organizacional formulada por Igarashi, Ensslin, Ensslin, Paladini, (2008, p. 119). Nesse conceito, uma Avaliação de Desempenho Organizacional deve investigar:

(i) o que vai ser avaliado - ou seja, conhecer o objeto da avaliação, incluindo aqui a sua identidade, a cultura sobre a qual esta identidade é construída, as instâncias que respondem pelo objeto a ser avaliado, resultando nos objetivos a serem perseguidos; (ii) como proceder à avaliação - ou seja, identificar como cada objetivo será avaliado e quanto cada objetivo contribui para a avaliação do todo, possibilitando a identificação do perfil de desempenho do objeto avaliado; (iii) como conduzir ao gerenciamento interno - com base na análise das fragilidades e potencialidades identificadas para sugerir ações de aperfeiçoamento - promovendo a alavancagem do desempenho institucional.

A partir desse conceito, a afiliação teórica deste trabalho assume que a Avaliação de Desempenho Organizacional é o processo de gestão utilizado para construir, fixar e disseminar conhecimentos por meio da identificação, organização, mensuração e integração dos aspectos de um determinado contexto, julgados relevantes para medir e gerenciar o desempenho dos objetivos estratégicos da organização (ENSSLIN e ENSSLIN. S, 2009). Para efeito desta pesquisa, a avaliação de desempenho se restringe às variáveis dos sistemas.

\subsection{Proposta Metodológica para incorporar a dimensão integrativa}

O ambiente organizacional pode ser caracterizado por um sistema e subsistemas, podendo, ainda, apresentar outros desdobramentos, de acordo com a estrutura da organização ou de seus processos de trabalho. Na perspectiva da avaliação do desempenho organizacional, o(s) decisor(es) pode(m) estabelecer um parâmetro macro ou micro, observados os diversos níveis hierárquicos presentes na organização.

No contexto de cada subsistema organizacional, observam-se as interrelações e interconexões com os demais subsistemas. O ponto de partida para a Avaliação de Desempenho Organizacional inicia-se com a análise da performance dos subsistemas organizacionais. Assim, o processo de avaliação do desempenho levará em consideração: (i) os aspectos relevantes para o desempenho do subsistema; (ii) os aspectos que um subsistema afeta o desempenho de outro subsistema; (iii) os aspectos que um subsistema é afetado pelo desempenho dos demais subsistemas; e (iv) a agregação dos desempenhos internos de cada subsistema e das interrelações e interconexões entre os diversos subsistemas. Destaca-se que esse processo deve ocorrer sem perda de foco da convergência com os macro- 
objetivos do sistema organizacional.

Cabe destacar também que a metodologia-base para o desenvolvimento do presente trabalho é fundamentada no MCDA Construtivista, devidamente apresentada na subseção 2.2 deste artigo.

Deve-se esclarecer que os modelos de Avaliação de Desempenho Organizacional (ADO), gerados com base na Metodologia MCDA-C, ajudam a construir o entendimento do decisor em relação à sua percepção da realidade. Tradicionalmente, no âmbito da avaliação do desempenho, a MCDA tem sido utilizada, com sucesso, na formulação de modelos para sistemas organizacionais, limitados à área de comando do decisor, sem a preocupação da integração das partes.

Assim, para fins do objetivo desta pesquisa, ou seja, a incorporação da dimensão integrativa no processo de avaliação de desempenho organizacional, a partir da ferramenta MCDA-C, propõe-se o desenvolvimento das seguintes etapas:

a) Identificação dos subsistemas organizacionais: esta etapa visa identificar os subsistemas organizacionais, a partir da estrutura organizacional e/ou dos processos de trabalho da organização.

b) Construção de um modelo de avaliação para cada subsistema, a partir da Metodologia MCDA-C: nesta etapa, deve-se conceber um modelo de avaliação de desempenho para cada subsistema organizacional. Assim a representação do modelo de avaliação de um subsistema é composta, no primeiro nível hierárquico, pelo objetivo maior do subsistema, ou seja, avaliar o seu desempenho, e, no segundo nível hierárquico, pelos seus objetivos estratégicos considerados relevantes pelo decisor. Destaca-se que, além do segundo nível hierárquico, outros podem ser desmembrados até o estágio passível de medição, ou seja, de construção dos descritores nos termos da MCDA-C, Fase de Estruturação.

c) Identificação das interrelações e interconexões existentes entre os diversos subsistemas no modelo de avaliação previsto no item anterior: esta terceira etapa visa à construção de um modelo de avaliação que contemple as interrelações e interconexões entre os diversos subsistemas, observando-se: (i) os aspectos em que um subsistema afeta o desempenho de outro subsistema (horizontal de causa); e, (ii) os aspectos em que um subsistema é afetado pelo desempenho de outro subsistema (horizontal de efeito).

d) Agregação das variáveis de desempenho (alíneas "b" e "c") em um único modelo: esta quarta etapa visa agregar, em um único modelo, os resultados das variáveis internas de desempenho de cada subsistema e das interrelações e interconexões entre os diversos subsistemas. Assim, observa-se que um subsistema possui variáveis de desempenho internas, isto é, exclusivas de sua área de atuação e aspectos interrelacionados com os demais subsistemas do ambiente organizacional. 
Nesse caso, um subsistema pode afetar o desempenho de outro subsistema ou ser por ele afetado. Este processo de interrelação, isto é, de influenciar ou ser influenciado, torna-se cada vez mais frequente no ambiente organizacional, dada a complexidade deste ambiente, a integração dos processos de trabalho e a competitividade das organizações.

e) Identificação das estratégias mais apropriadas para o sistema como um todo: esta quinta etapa visa, a partir do perfil de desempenho de cada subsistema e do sistema organizacional como um todo, identificar as estratégias de aperfeiçoamento mais adequadas para o sistema. Com isso, permite-se, de forma transparente, identificar quais escolhas estratégicas, considerando-se as variáveis de desempenho (internas e interrelacionais) de cada subsistema, são mais adequadas para um melhor desempenho do sistema como um todo, possibilitando um equilíbrio dinâmico e global.

Nesse sentido, o sistema organizacional pode fazer valer sua hierarquia e, mesmo delegando autonomia para cada subsistema atuar da melhor maneira possível no contexto interno, controlar e supervisionar suas interrelações, visando orientar os esforços, prioritariamente, para o alcance dos objetivos do todo. Assim, cada parte (subsistema) demandará mais energia nos aspectos que terão maior impacto no resultado global do sistema, por exemplo, cada subsistema, na medida em que se depara com duas alternativas pontuais: aperfeiçoar o seu desempenho interno em determinado aspecto, ou contribuir para que outro subsistema tenha um melhor desempenho, deverá ser orientado para optar pela alternativa que apresentar maior contribuição para o desempenho global do sistema.

Em síntese, a incorporação da dimensão integrativa no processo de Avaliação de Desempenho Organizacional (ADO) tem como foco a busca da melhor forma para se obter o máximo desempenho global do sistema organizacional, em que se potencializa a participação de cada parte (subsistema) na melhoria das variáveis de seu desempenho interno e/ou, principalmente na ênfase das interrelações.

Com isso, constata-se a potencialidade da dimensão integrativa, associada à Metodologia MCDA Construtivista, no processo de avaliação de desempenho organizacional. Tal potencialidade se explica pela agregação cumulativa de variáveis, culminando na possibilidade de consideração do equilíbrio dinâmico e global do sistema. Cabe esclarecer que o equilíbrio dinâmico e global do sistema organizacional se dá pela conjunção de esforços, na escolha de estratégias mais apropriadas para o sistema como um todo.

Destaca-se ainda que na visão de sistemas fechados, proposta por Maturana e Varela (1997), os sistemas, para evoluírem, devem ter a capacidade de, além de desempenharem suas atividades funcionais de maneira competitiva, devem intercambiar energia com o exterior em uma forma endotérmica. Maturana e Varela 
(1997) ainda afirmam que esse intercâmbio deve ser regulado pelos interesses do sistema maior, o qual está contemplado igualmente na MCDA-C, incorporada a dimensão integrativa, quando propõe a avaliação e gestão do processo de intercâmbio por meio da figura hierárquica superior (sistema maior), sem tolher a liberdade e iniciativa dos subsistemas, tanto no que se refere ao desempenho de suas atividades internas, quanto à forma de alcançar o desempenho de seus interrelacionamentos.

\section{Resultados e Análises: operacionalização da proposta metodológica de ADO considerando a dimensão integrativa a uma empresa da área de tele- comunicações}

Nesta seção, apresenta-se o estudo de caso realizado no presente artigo, focando o processo que a empresa da área de telecomunicações realizou para implementar a proposta de avaliação de seu desempenho considerando a dimensão integrativa.

A situação problemática a ser investigada foi selecionada a partir da conjunção de dois fatores: (i) o interesse dos gestores da empresa em buscar novas formas de avaliação do desempenho da própria organização, condizentes com as percepções dos atores que a compõem; (ii) o interesse do autor da proposta metodológica de adoção da dimensão integrativa em processos de avaliação de desempenho, em verificar a aplicabilidade da metodologia em uma situação real do contexto organizacional.

O presente estudo de caso foi desenvolvido na Gerência de Logística da empresa que envolve as Supervisões de Compras, de Logística de Suprimentos, de Expedição e de Planejamento e Controle da Produção (PCP). Dentre essas supervisões, elegeu-se a aplicação integral da dimensão integrativa à Supervisão de Planejamento e Controle da Produção (PCP), devido às seguintes características: (i) o PCP possui forte interação com várias áreas da empresa, principalmente com as demais supervisões vinculadas à Gerência de Logística; (ii) sua performance é fundamental para o processo produtivo da empresa e para o desempenho das demais áreas com as quais mantém relação de trabalho; (iii) precisa ter seu desempenho constantemente avaliado para responder, de maneira mais eficaz, às demais áreas da empresa; (iv) a área influencia e é influenciada por várias áreas da empresa, o que demanda um processo de avaliação nitidamente integrativo.

Como a metodologia-base é a MCDA, ela ditará as etapas de construção do modelo. Entretanto, uma vez que, tradicionalmente, a MCDA enfatiza a área de comando do decisor (variáveis internas de desempenho) e uma vez que este estudo se preocupa também com a integração das partes do sistema, a construção do modelo consorcia a metodologia-base com novas etapas de construção, apre- 
sentadas na subseção 2.2 desta pesquisa.

Destaca-se que a ênfase da ilustração vai apresentar a incorporação da dimensão integrativa na Metodologia MCDA Construtivista, motivo pelo qual a construção do modelo de avaliação para as variáveis internas de desempenho do PCP não serão demonstradas, por caracterizar-se a aplicação direta da MCDA-C. No entanto, serão explicitadas na apresentação do perfil de desempenho do PCP - subseção 4.2.5.

\subsection{Construção do Modelo de Avaliação}

A construção do modelo de avaliação de desempenho inicia-se pela caracterização dos subsistemas organizacionais que serão objeto do processo de avaliação. Assim, a primeira etapa da Metodologia MCDA-C é caracterizada pela identificação dos subsistemas organizacionais.

No contexto da empresa onde foi realizado o presente estudo de caso, a Figura 2 contempla os subsistemas organizacionais selecionados para o processo de Avaliação de Desempenho Organizacional (ADO).

Figura 2: O sistema e os subsistemas organizacionais com as áreas de integração

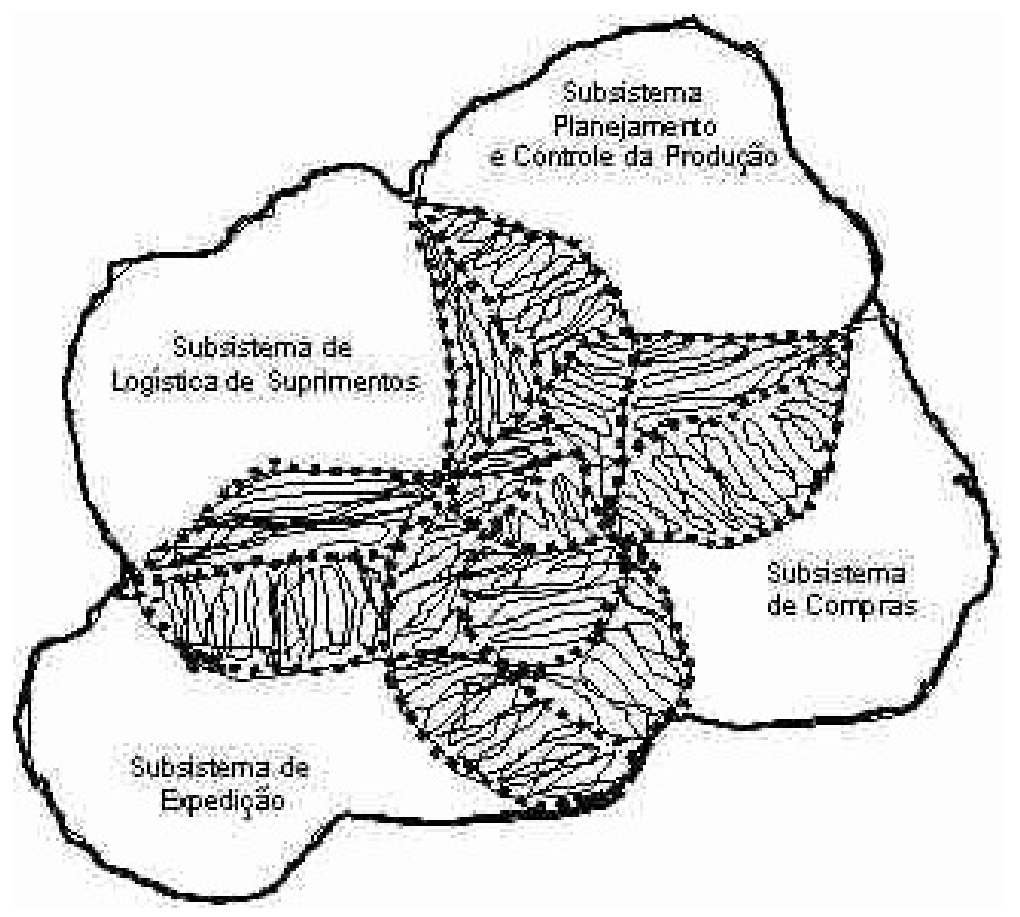

Fonte: Elaborada pelos autores.

Como pode ser observado na Figura 2, ficam caracterizadas as interações e interconexões existentes entre os diversos subsistemas apresentados, onde um afeta e é afetado pelo desempenho dos demais. 


\subsection{Estruturação do modelo de avaliação da área Dimensão Integrativa - DI}

No presente estudo, a dimensão integrativa envolve as variáveis em que o PCP afeta o desempenho de outros subsistemas (supervisões de Compras, Logística de Suprimentos e Expedição) e, também, as variáveis dos respectivos subsistemas que afetam o desempenho do PCP.

O principal objetivo da etapa de estruturação é organizar, desenvolver e expandir o conhecimento dos decisores a respeito do contexto decisional, por meio de uma visão construtivista que pressupõe a produção de conhecimentos a partir da participação dos atores no processo. Nesse sentido, não há uma verdade a ser descoberta, mas o conhecimento é construído com base no sistema de valor, convicções e objetivos dos envolvidos.

O processo de identificação das variáveis em que o PCP afeta o desempenho de outros subsistemas foi conduzido da seguinte forma: (i) encontro inicial com os decisores de cada subsistema, oportunidade em que o facilitador explicitou os objetivos pretendidos e apresentou o modelo de avaliação de desempenho do PCP, visando facilitar o entendimento, garantir uniformidade e evitar perda de foco no decorrer das discussões; (ii) encontros subsequentes com os decisores de cada subsistema, ocasião em que o facilitador estimulou verbalização livre e aberta, sobre a seguinte questão: Em quais aspectos o PCP afeta o desempenho da supervisão sob sua responsabilidade? Os encontros foram devidamente gravados, e o facilitador, após organizar e sistematizar as informações, procedia à validação com os decisores, até o reconhecimento final de que as variáveis identificadas representavam as suas percepções.

Assim, por esses procedimentos, simultaneamente procedeu-se à identificação dos Elementos Primários de Avaliação - EPAs e ao devido agrupamento por áreas de interesse.

Procurou-se identificar os aspectos mais representativos em que o PCP afeta o desempenho das referidas supervisões. Assim, ficou evidente que a influência do PCP pode se dar de forma direta ou indireta, com diferentes níveis de intensidade, o que, em alguns momentos, gerava dificuldades na caracterização das variáveis.

Dando-se continuidade ao processo de elaboração do modelo de avaliação do desempenho do PCP, passa-se a apresentar a Construção da Árvore de Valor para cada supervisão, no que se refere aos aspectos em que o PCP afeta o desempenho das demais supervisões.

\subsubsection{Construção da Árvore de Valor da Dimensão Integrativa - DI}


Inicialmente, na Figura 3, pode-se obter uma visão global da Arvore de Valor, onde se constata as variáveis em que o PCP afeta o desempenho dos demais subsistemas, ou seja, as Supervisões de Compras, Logística de Suprimentos e Expedição. Apesar de a figura ser ilegível, o objetivo é demonstrar a abrangência da DI.

Figura 3: Visão global das variáveis em que o PCP afeta o desempenho das Supervisões de Compras, Logística de Suprimentos e Expedição

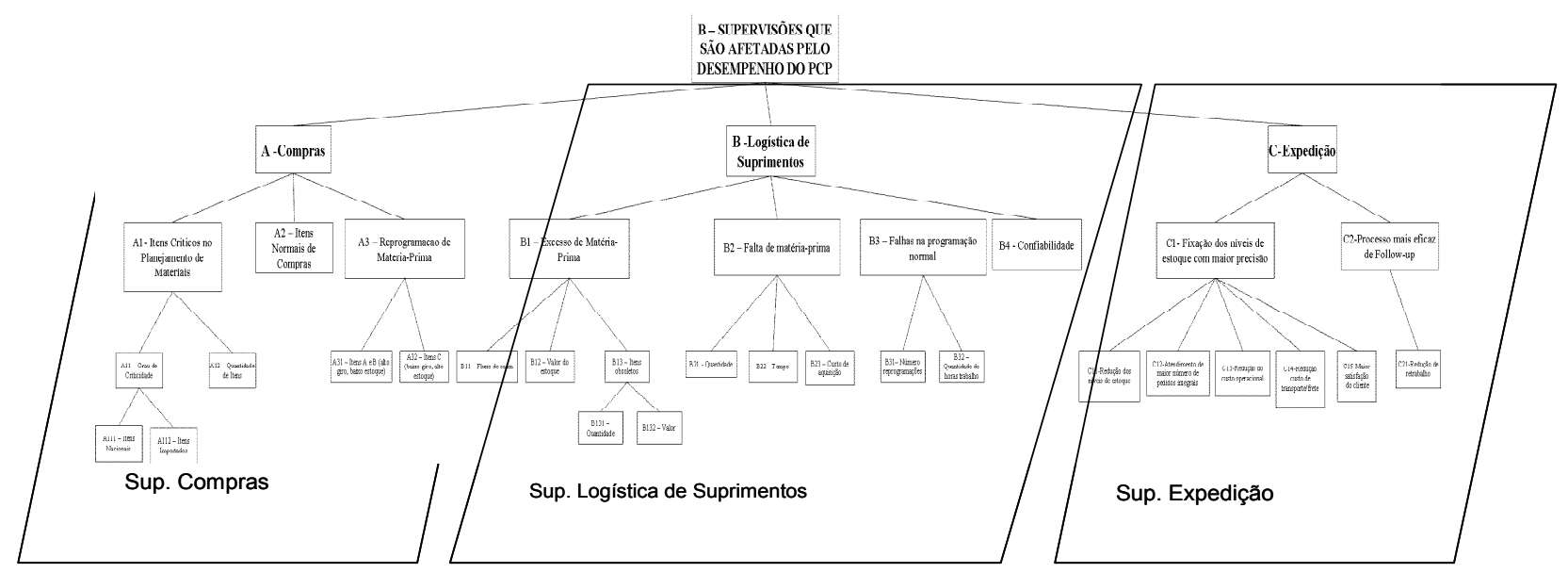

Fonte: Elaborada pelos autores.

A partir da visão global constante na Figura 3, apresenta-se somente um recorte do modelo global representado pela Supervisão de Compras, conforme é visualizado na Figura 4.

Figura 4: Árvore de Valor dos aspectos em que o PCP afeta o desempenho da Supervisão Compras

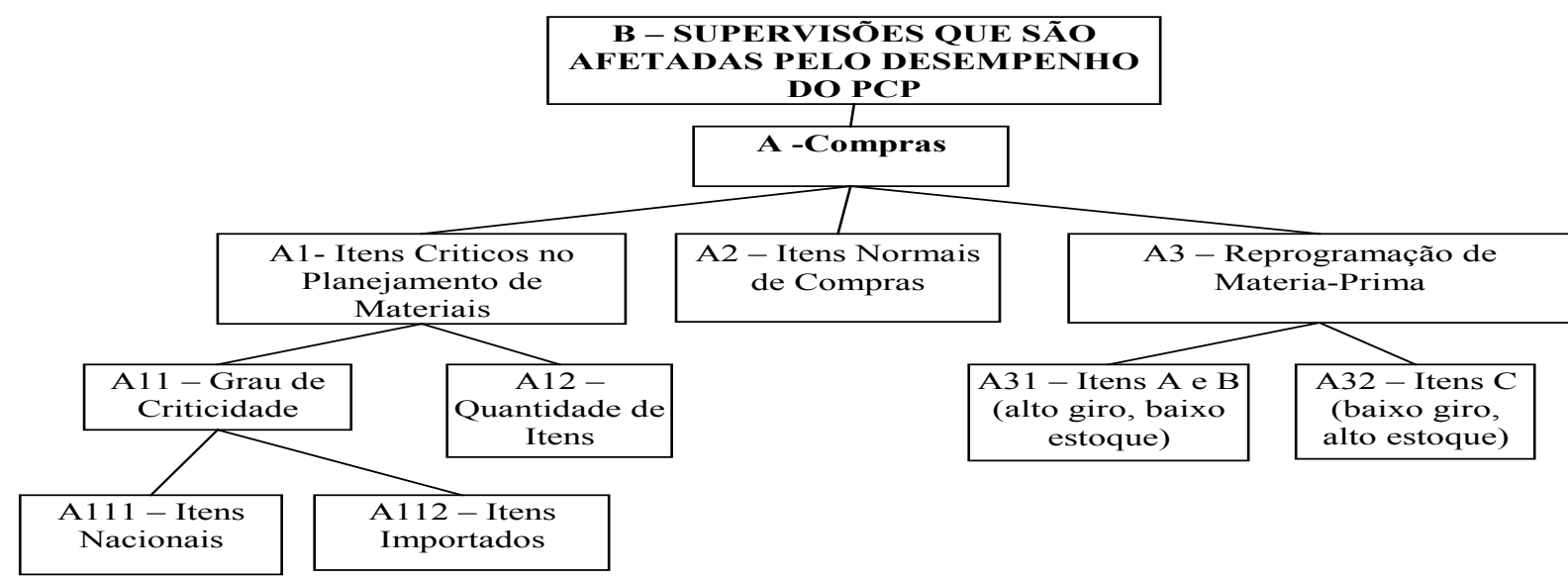

Fonte: Elaborada pelos autores.

Como se observa na Figura 4, o PCP influencia o desempenho da Supervisão de Compras nos seguintes aspectos: Definição de Itens Críticos no Planejamento de Materiais, Itens Normais de Compras e Reprogramação de 
Matéria-Prima. Os Itens Críticos no Planejamento de Materiais são representados pelo Grau de Criticidade e pela Quantidade de Itens. Quanto à Reprogramação de Matéria-Prima, esta é explicada pelos Itens de Materiais, classificados no tipo A e B (alto giro e baixo estoque) e em relação aos Itens de Estoque classificados no tipo $\mathrm{C}$ (baixo giro e alto estoque).

Após a adoção desse procedimento para as demais supervisões, conclui-se a apresentação das áreas em que o PCP afeta o desempenho das demais supervisões. A seguir, inicia-se a apresentação do processo inverso, ou seja, das variáveis em que o PCP tem seu desempenho afetado pela atuação das respectivas áreas, ainda no contexto da exploração da Dimensão Integrativa, proposta neste trabalho.

No desenvolvimento desta etapa, foram adotados os mesmos procedimentos da etapa anterior, ou seja, a realização de vários encontros com os decisores de cada supervisão. Sua execução tornou-se mais fácil, tanto para os decisores quanto para o facilitador, devido à prática com o desenvolvimento da etapa antecedente e, principalmente, em função do aprendizado e da geração de conhecimentos. Observa-se, nesse aspecto, o caráter construtivista da metodologia adotada na prática.

Na Figura 5, pode-se obter uma visão global da Árvore de Valor, onde são constatadas as variáveis representativas das Supervisões de Compras, Logística de Suprimentos e Expedição que afetam o desempenho do PCP. Apesar de a figura ser ilegível, o objetivo é demonstrar a abrangência da Dimensão Integrativa.

Figura 5: Visão geral da Árvore de Valor dos aspectos em que as Supervisões de Compras, Logística de Suprimentos e Expedição afetam o desempenho do PCP

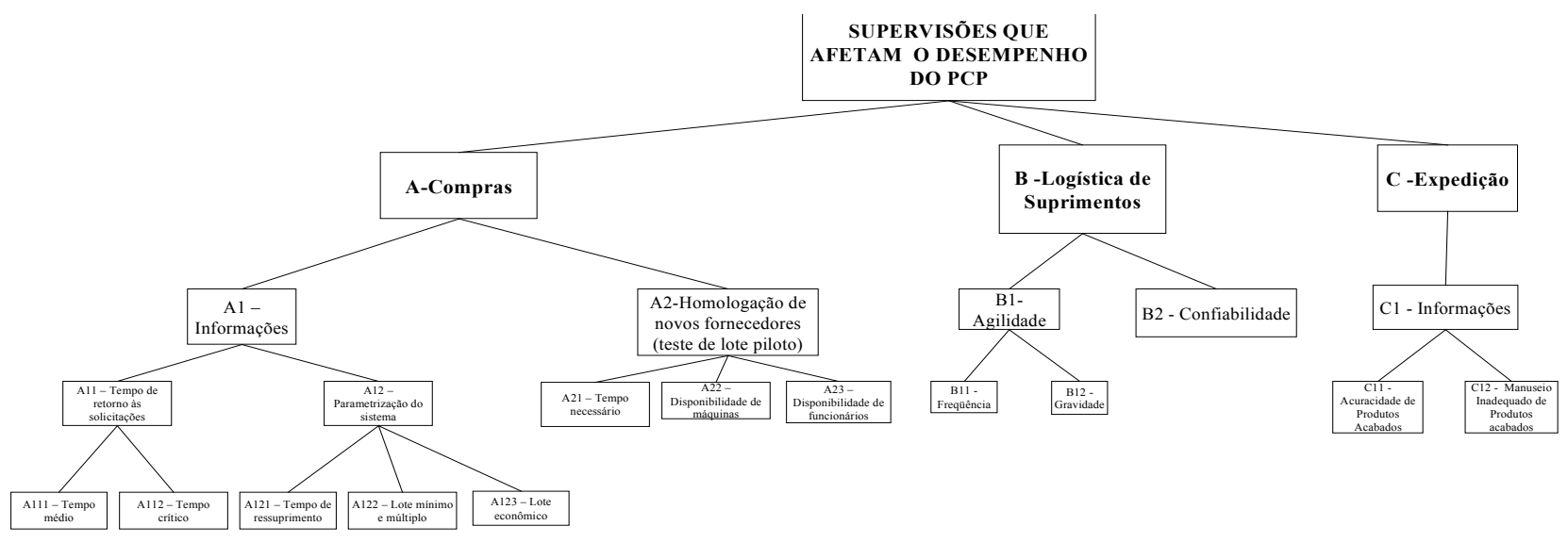

Fonte: Elaborada pelos autores.

A partir da visão global constante na Figura 5, apresenta-se somente um recorte do modelo global representado pela Supervisão de Compras, conforme a Figura 6. 
Figura 6: Arvore de Valor dos aspectos em que a Supervisão de Compras afeta o desempenho do PCP

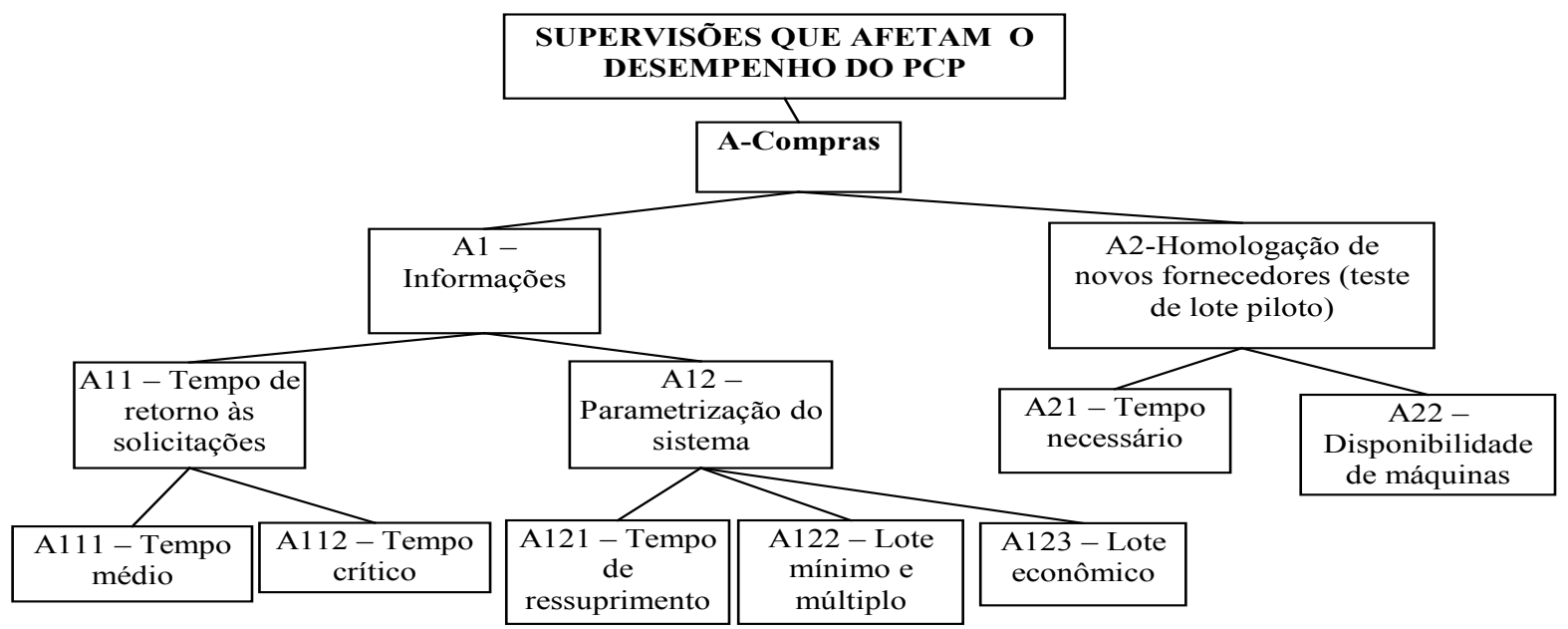

Fonte: Elaborada pelos autores.

Como pode ser observado na Figura 6, a Supervisão de Compras afeta o desempenho do PCP em termos de Informações e na Homologação de Novos Fornecedores (teste piloto). A variável Informações é representada pelo Tempo de Retorno às Solicitações e pelos dados relativos à Parametrização do Sistema. O Tempo de Retorno às Solicitações é explicado pelo Tempo Médio e pelo Tempo Crítico. Já a Parametrização do Sistema é representada pelas variáveis Tempo de Ressuprimento e definição de Lote Mínimo, Múltiplo e Lote Econômico.

No que se refere à Homologação de Novos Fornecedores (teste piloto), esta é representada pelo Tempo Necessário para a Realização do Teste, Disponibilidade de Máquinas e Disponibilidade de Funcionários.

Assim, elaborou-se a Árvore de Valor das variáveis em que as Supervisões de Compras, Logística de Suprimentos e Expedição, devido às suas atribuições e responsabilidades, afetam o desempenho do PCP. Pode ser constatado que, ao contrário da situação discutida na parte inicial desta subseção, as variáveis em que o PCP é afetado são em menor número: o fluxo de atividades e demandas originam-se tipicamente no PCP, o que explica a direção das influências.

\subsubsection{Construção dos Descritores da Dimensão Integrativa - DI}

A Construção dos Descritores para a área de Integração será iniciada pelos aspectos em que o PCP afeta o desempenho dos demais subsistemas (Supervisões de Compras, Logística de Suprimentos e Expedição).

Constata-se, ainda, na Figura 7, a identificação de dois níveis de impacto para cada descritor. O nível superior corresponde ao nível 'BOM' (B), ou seja, corresponde à fronteira entre os desempenhos de excelência (superior ao nível 
'BOM') e de mercado (inferior ao nível 'BOM'). Já o nível inferior corresponde ao nível 'NEUTRO' $(\mathrm{N})$, isto é, identifica a fronteira entre os desempenhos de mercado (superior ao nível 'NEUTRO') e comprometedor (inferior ao nível 'NEUTRO'). Assim, a performance do PCP, de forma local (em cada descritor) ou global (considerando todo o modelo), ao impactar em resultado superior ao nível 'BOM', corresponde a um desempenho de excelência; entre os níveis 'BOM' e 'NEUTRO', corresponde a um desempenho de mercado; e, finalmente, se inferior ao nível 'NEUTRO', corresponde a um desempenho comprometedor.

Na Figura 7, são apresentados os descritores da Supervisão de Compras.

Figura 7: Construção dos Descritores das variáveis que o PCP afeta a Supervisão de Compras

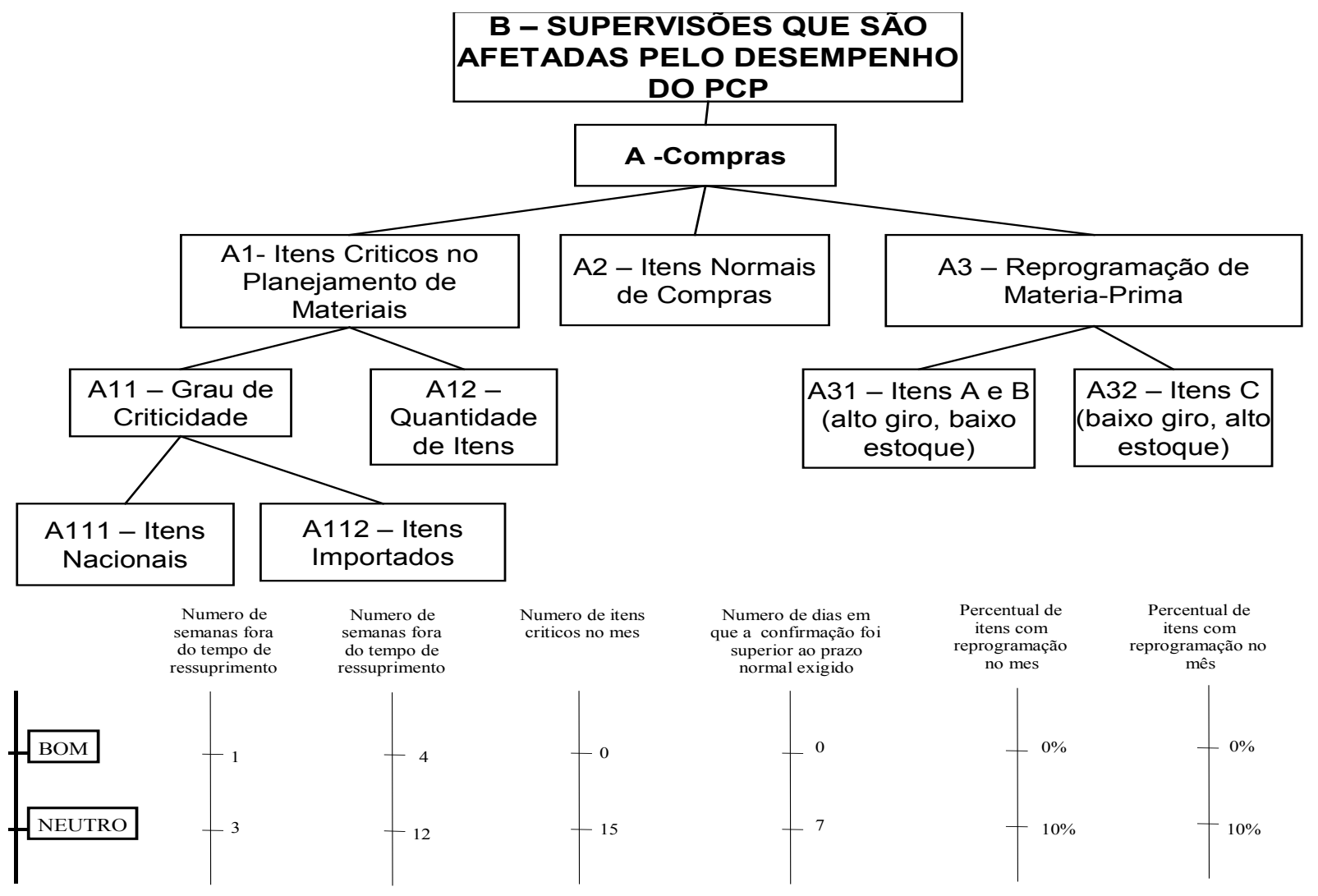

Fonte: Elaborada pelos autores.

Constata-se, na Figura 7, a construção de seis descritores decorrentes da influência que o PCP possui na Supervisão de Compras. Os descritores são diretos, contínuos e quantitativos.

Assim, após a adoção dos mesmos procedimentos para as demais áreas, conclui-se a apresentação da Construção dos Descritores em que o PCP afeta o desempenho das demais supervisões, vinculadas à Gerência de Logística. Completando a apresentação das variáveis em que o PCP mantém conexões com as demais supervisões, passa-se para a Construção dos Descritores das variáveis em que esta supervisão é afetada por Compras, Logística de Suprimentos e Expedição. 
Também para esta etapa, foram utilizados os mesmos procedimentos da subseção anterior. Observam-se, na forma de descritores, as variáveis em que a Supervisão de Compras afeta o desempenho do PCP.

Figura 8: Construção dos Descritores que a Supervisão de Compras afeta o desempenho do PCP

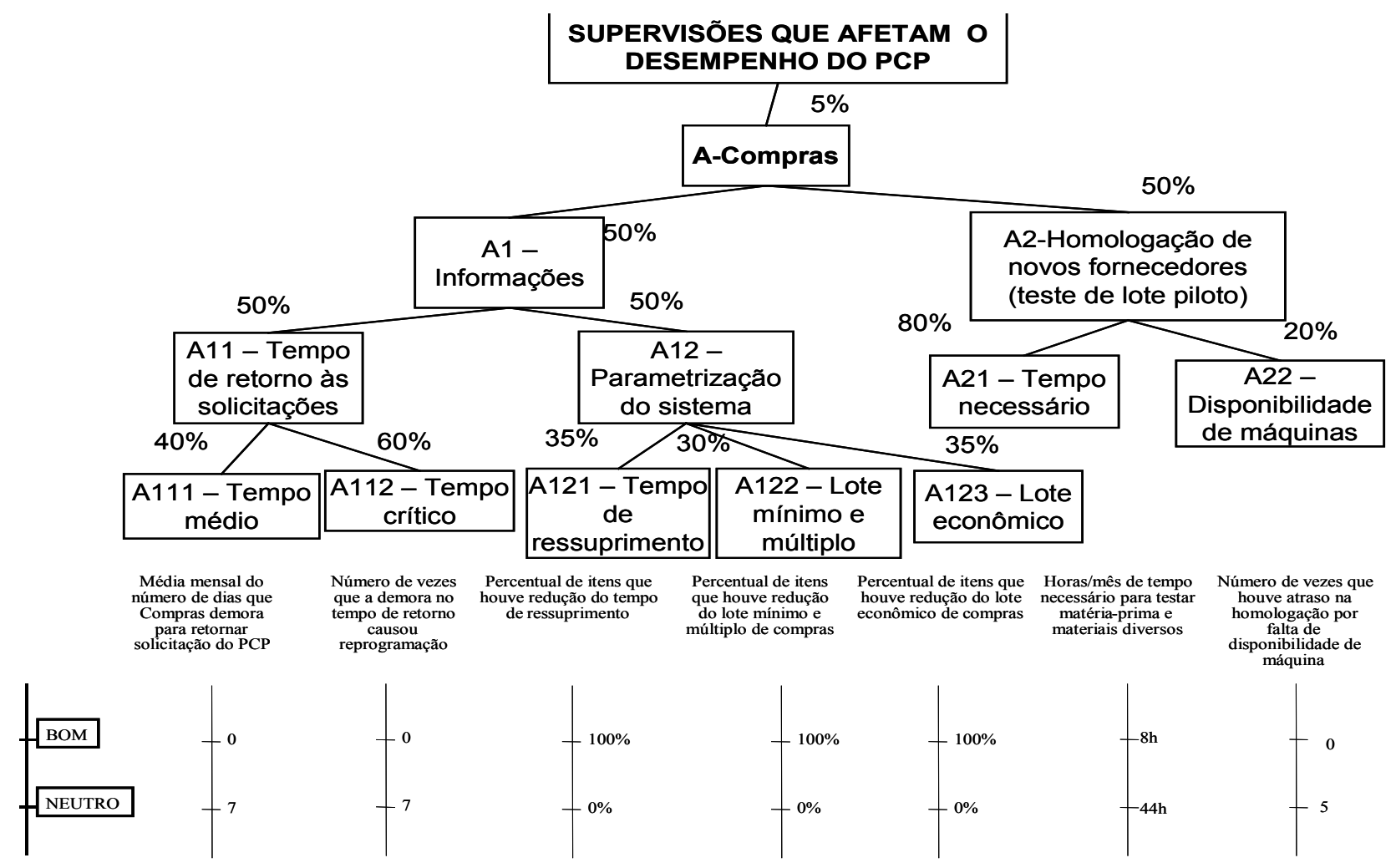

Fonte: Elaborada pelos autores.

Como pode ser observado na Figura 8, foram construídos sete descritores diretos, contínuos e quantitativos, para esta conexão.

A Fase de Avaliação consiste na mensuração das ações potenciais, e envolve quatro procedimentos: (i) Construção da Função de Valor; (ii) Identificação das Taxas de Compensação; (iii) Identificação do Perfil de Impacto das Ações; e, (iv) Análise dos Resultados. Cada um deles será tratado, separadamente, a seguir.

\subsubsection{Construção das Funções de Valor}

A construção de uma função de valor para cada PVF visa ordenar a intensidade de preferência (diferença de atratividade) entre pares de níveis de impacto ou ações preferenciais. Nesse sentido, a Função de Valor é um instrumento para auxiliar os decisores a expressarem, de forma numérica, suas preferências. Tratase de uma representação matemática, em forma de gráfico ou de escala numérica, que tem por objetivo demonstrar o quanto um nível de impacto é preferível, em relação a outro nível. 
De acordo com Ensslin, et al. (2001), a literatura apresenta diversos métodos para a construção de Funções de Valor, dentre os quais destacam-se: Pontuação Direta (Direct Rating), Bissecção e Julgamento Semântico. Para fins de construção das Funções de Valor do modelo de avaliação, objeto deste trabalho, será utilizado o método Pontuação Direta (ver ENSSLIN, et al., 2001, p. 190).

Com base no método Pontuação Direta, por opção dos decisores, foram construídas as Funções de Valor de forma linear. Para tanto, os níveis de ancoragem ('BOM' e 'NEUTRO') foram fixados - o nível 'BOM' correspondendo a 100 (cem) e o nível 'NEUTRO' correspondendo ao 0 (zero) - sendo as escalas geradas pela equação $\mathrm{f}(\mathrm{x})=\alpha \mathrm{x}+\beta$. Cumpre esclarecer que as escalas utilizadas, neste estudo de caso, constituem-se como escalas de intervalos (ver ENSSLIN et al., 2001).

Com a construção das Funções de Valor, torna-se possível proceder à avaliação local: cada ação pode ser avaliada em cada objetivo. Entretanto, a avaliação global ainda não pode ser realizada. Para tal fim, necessita-se da identificação das taxas de compensação que permitirão que as unidades de avaliação local (em cada objetivo) sejam transformadas em unidades de avaliação global. Torna-se possível, então, agregar essas unidades de avaliação local, obtendo-se, assim, a avaliação global total de uma ação.

\subsubsection{Identificação das Taxas de Compensação entre os objetivos}

As Taxas de Compensação de um modelo multicritério de avaliação expressam, segundo o julgamento dos decisores, a perda de performance que uma ação potencial deve sofrer em um critério para compensar o ganho de desempenho de outro (BOUYSSOU, 1986; KEENEY, 1992; RAY, 1996, ENSSLIN et al, 2001).

Com base na literatura, algumas abordagens têm sido propostas para a determinação das Taxas de Compensação, entre as quais se pode citar o clássico "Trade-off Procedure" (BODILY, 1985; Von WINTERFELDT e EDWARDS, 1986; WATSON \& BUEDE, 1987; KEENEY, 1992; BEINAT, 1995), o "swing procedure" (VON WINTERFILD e EDWARDS, 1986), e o "MACBETH" (BANA; COSTA e VANSNICK, 1995c; 1995d; 1995e; 1995f; 1995g).

No presente estudo de caso, a identificação das Taxas de Compensação do modelo foi gerada pelo método Trade-Off, que consiste em comparar as ações fictícias com desempenhos diferentes em apenas dois critérios e com desempenho idênticos nos demais. Destaca-se que, nos dois critérios citados, uma ação possui o nível de impacto 'bom' no primeiro critério e 'neutro' no segundo, enquanto que uma segunda ação possui o nível 'neutro' no primeiro critério e o 'bom' no segundo. Escolhendo qual das duas ações é a preferida, os decisores decidem qual 
Na Figura 9, apresentam-se as taxas de substituição das variáveis da Área de Integração (DI), especificamente nos aspectos em que o PCP afeta o desempenho de Compras.

Figura 9: Taxas de Substituição da Supervisão de Compras que são afetadas pelo desempenho do PCP

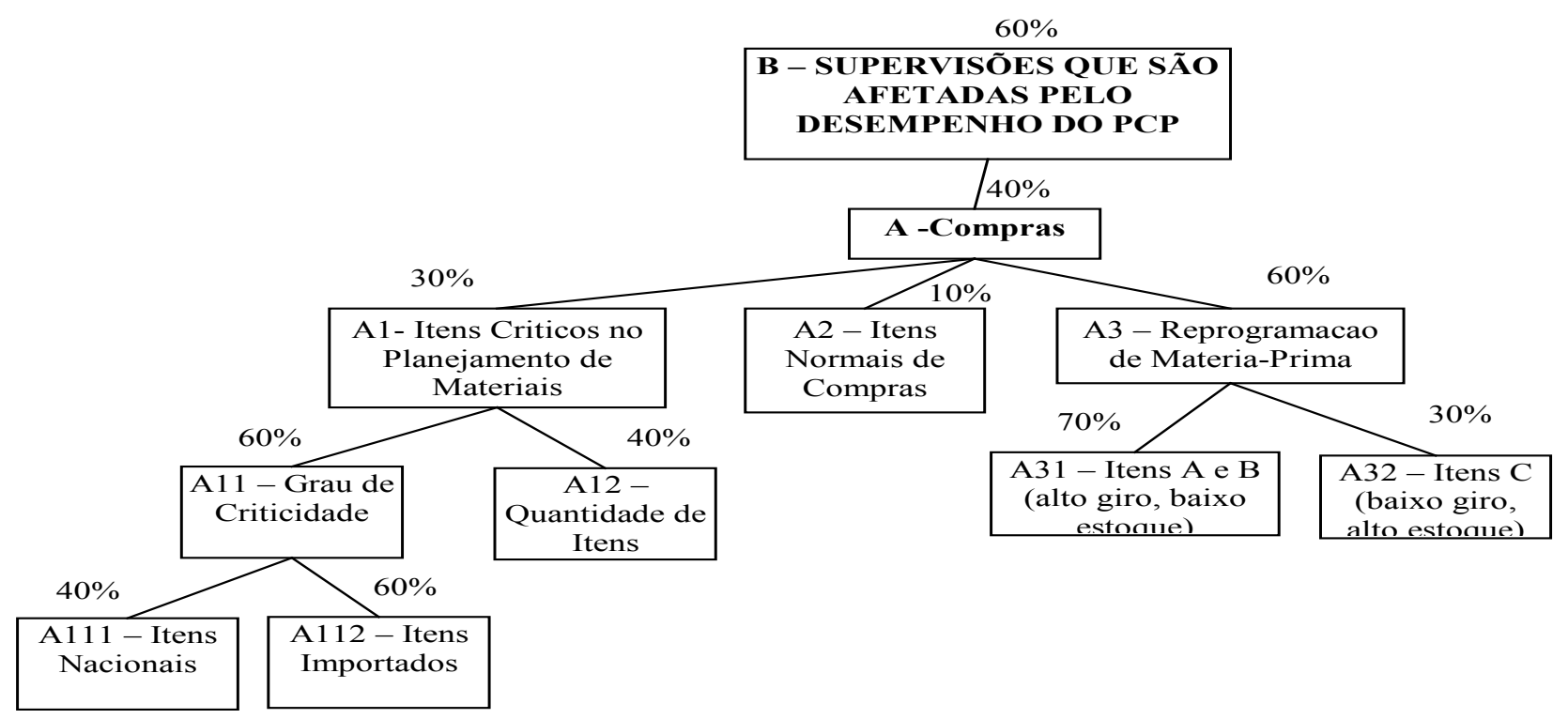

Fonte: Elaborada pelos autores.

Com relação à Supervisão de Compras, a influência do PCP ocorre por meio das variáveis Itens Críticos no Planejamento de Materiais, com a taxa de 30\%; Itens Normais de Compras, com 10\%; e Reprogramação de Matéria-Prima, com $60 \%$, com os devidos desmembramentos conforme se pode observar na Figura 9. Assim, esta etapa foi aplicada para todas as supervisões, objeto de estudo, que afetam ou são afetadas pelo desempenho do PCP.

\subsubsection{Identificação e análise dos perfis de desempenho do PCP}

Nesta subseção, é possível apresentar o perfil de desempenho local e global do PCP, considerando-se as variáveis internas e a DI. O perfil de desempenho local leva em consideração o desempenho de um PVF específico ou PVE. Já o perfil de desempenho global leva em consideração todos os PVFs, por meio de um processo de agregação.

Inicialmente, procedeu-se ao processo de coleta de dados junto às Supervisões do PCP, Compras, Logística de Suprimentos e Expedição. Esse processo foi realizado em encontros com os decisores das respectivas supervisões, tendo-se adotado os seguintes critérios: (i) para as informações de desempenho disponíveis, estas foram analisadas criticamente e incorporadas no modelo; (ii) para as 
informações não imediatamente disponíveis, os decisores apresentam previsões, com base em suas experiências referentes ao cotidiano da empresa.

A seguir, inicia-se o processo de apresentação e discussão do perfil de desempenho do PCP, tendo-se como ponto de partida o desempenho global, em nível dos PVFs, como pode ser observado na Figura 10.

Figura 10: Perfil global de desempenho do PCP nos PVFs

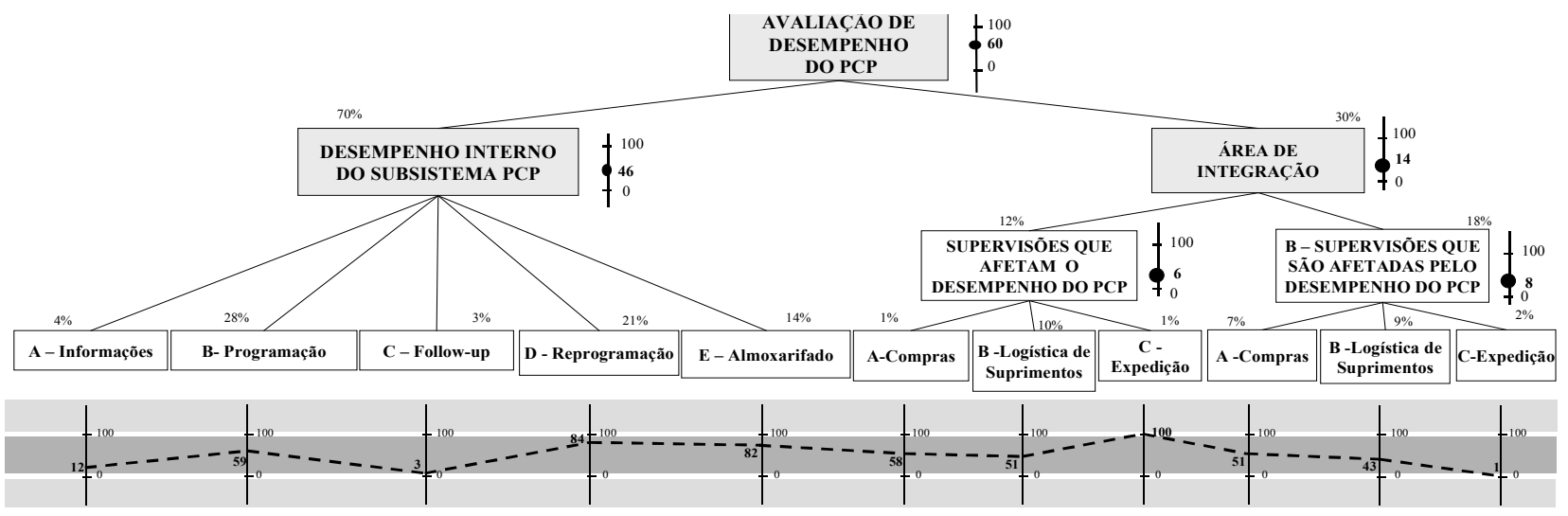

Fonte: Elaborada pelos autores.

Observa-se, na Figura 10, o perfil global de desempenho do PCP, que corresponde a 60 pontos. Essa pontuação caracteriza o desempenho como de 'mercado', pois se situa entre os níveis 'NEUTRO' e 'BOM'.

Analisando a área Desempenho Interno, observa-se que esta atingiu 46 pontos. Já a performance da área DI, por sua vez, alcançou 14 pontos, sendo 6 pontos referentes às supervisões que afetam o desempenho do PCP e 8 pontos referentes às supervisões que são afetadas pelo desempenho do PCP. Em relação ao Desempenho Interno do PCP, cada PVF obteve o seguinte nível de desempenho: PVF - Informações, 12 pontos; PVF - Programação, 59 pontos; PVF - Follow-up, 3 pontos; $\mathrm{PVF}$ - Reprogramação, 83 pontos; e, o PVF - Almoxarifado, 82 pontos. Quanto à DI, no que se refere às supervisões que afetam o desempenho do PCP, o PVF - Compras atingiu 59 pontos; PVF - Logística de Suprimentos, 51 pontos; e, Expedição, 100 pontos. Quanto às supervisões que são afetadas pelo desempenho do PCP, tem-se o seguinte nível de desempenho: PVF - Compras, 51 pontos; PVF Logística de Suprimentos, 43 pontos e o PVF - Expedição, 1,0 ponto.

Um comentário faz-se necessário neste ponto, no que se refere ao caráter de mutualidade da DI. Por sua natureza, a ação da DI deveria ocorrer em 'mãodupla'. Ou seja, seria de se esperar que a Dimensão Integrativa operasse, de forma equilibrada, nas duas direções - do PCP para as supervisões e vice-versa. Entretanto, como pode ser constatado na Figura 10, esta mutualidade nem sempre ocorreu de forma equilibrada. Em termos gerais, observa-se que a contribuição 
conjunta das três supervisões para o PCP é de 6,0 pontos, enquanto a contribuição do PCP para tais supervisões é de 8,0 pontos.

Pode-se observar o desequilíbrio da DI em relação à conexão do PCP com cada supervisão, separadamente. A Expedição vem contribuindo com o PCP em nível 'BOM'; entretanto a mutualidade não é observada, uma vez que o PCP contribui para esta área no nível mínimo. Compras, por sua vez, contribui com o PCP em, apenas, 1 ponto, enquanto recebe, do PCP, a contribuição de 4 pontos. Uma situação similar de desequilíbrio na DI ocorre na relação do PCP com a Logística de Suprimentos: esta supervisão contribui com o PCP em 5 pontos, enquanto é por ele afetada em 4 pontos.

4.2.6 Identificação das estratégias mais apropriadas para o sistema como um todo

A partir da análise da Figura 10, observa-se que a dimensão integrativa entre o PCP e as diversas supervisões poderia ser mais equilibrada. Obviamente, a decisão de otimizar a contribuição das áreas para o PCP e vice-versa constitui uma escolha estratégica do gestor do sistema, que tomará sua decisão levando em conta a repercussão ou impacto no desempenho global. Mas é fato inegável que, a partir do modelo construído, o gestor dispõe de uma ferramenta consistente e confiável para conseguir dimensionar o 'quanto', ou seja, o impacto local ou global no desempenho do PCP como um todo. Em outras palavras, a construção do modelo nas bases sugeridas demonstra ser uma ferramenta de geração de aprendizagem e apoio à decisão.

Neste contexto, como argumento principal deste trabalho, o desempenho organizacional resulta da soma das partes, beneficiando-se do conhecimento construído, das interrelações e das interconexões e, finalmente, da conjunção de esforços dos diversos subsistemas, possibilitando gerar um equilíbrio dinâmico e global.

\section{Considerações Finais}

O presente trabalho teve por objetivo apresentar e operacionalizar, por meio de um estudo de caso em uma empresa da área de telecomunicações, uma proposta metodológica que permite incorporar a dimensão integrativa nos processos de Avaliação do Desempenho Organizacional. Os autores desta proposta ao reconhecerem a incorporação da dimensão integrativa objetivaram demonstrar que é possível avaliar o desempenho de uma organização a partir de seus subsistemas, permitindo alavancar a melhoria do desempenho e da escolha de estratégias que melhor potencializem a performance do sistema organizacional como um todo. 
Este trabalho de caráter exploratório, deu continuidade à proposta de Sannemann (2001) e Ensslin.S, (2002) no sentido de expandir a contribuição do processo de Avaliação do Desempenho Organizacional (ADO) ao propor um processo, por meio da metodologia MCDA-C, capaz de incorporar as variáveis dos subsistemas que afetam seu desempenho, bem como as variáveis do seu próprio sistema. Tal processo sistematizado foi operacionalizado, e assim foi construído o modelo de ADO de uma empresa específica da área de telecomunicações.

Por meio da operacionalização do estudo de caso, a incorporação da dimensão integrativa permitiu o alcance dos seguintes resultados: (i) identificar as variáveis que um subsistema afeta e é afetado pelo desempenho de outro subsistema; (ii) dispor de informações para orientar cada subsistema, à medida que se deparar com duas alternativas pontuais - ou aperfeiçoar o seu desempenho interno em determinado aspecto, ou contribuir para que outro subsistema tenha um melhor desempenho - opte pela alternativa que apresentar maior contribuição para o desempenho global do sistema; (iii) identificar quais escolhas estratégicas são mais adequadas, para um melhor desempenho do sistema como um todo; e (iv) estimular e garantir um processo de comunicação constante entre os diversos subsistemas e o sistema organizacional.

Sintetizando, a incorporação da dimensão integrativa no processo de avaliação de desempenho organizacional tem como foco a busca da melhor forma para se obter o máximo desempenho global do sistema organizacional, em que se potencializa a participação de cada parte (subsistema) na melhoria das variáveis de seu desempenho interno e/ou, principalmente, na ênfase nas interrelações e interconexões. Assim, cada parte (subsistema) constituinte estará focada na alavancagem do melhor rendimento global do sistema, tornando-o superior à soma das partes.

Cumpre observar que a identificação dos efeitos advindos da incorporação da dimensão integrativa na sua totalidade é complexa e explica uma das limitações de sua aplicabilidade, sobretudo no que diz respeito à resistência das organizações em adotar uma perspectiva sistêmica em seus processos de gestão.

Como limitações da presente pesquisa, apontam-se os seguintes aspectos: (i) a proposta foi apenas operacionalizada - construiu-se o modelo de avaliação do desempenho de uma empresa da área de telecomunicações, considerando a dimensão integrativa, sem um acompanhamento de sua implementação; e (ii) a proposta foi operacionalizada apenas em uma empresa, sem a possibilidade de comparação dos efeitos ocorridos na empresa aqui selecionada com aqueles de uma outra organização. Com base nas limitações apontadas, sugerem-se os seguintes tópicos para futuras pesquisas: (i) acompanhamento do modelo construído, no sentido de proceder-se ao monitoramento do desempenho da empresa, a partir da incorporação da dimensão integrativa, com vistas a verificar a ocorrência, ou 
não, de sua alavancagem; e (ii) replicação da proposta apresentada em outros sistemas (organizações).

\section{Referências}

BANA e COSTA, C. A. Introdução Geral às Abordagens Multicritério de Apoio à Tomada de Decisão. Investigação Operacional, v. 66, p. 117-139, jun., 1988.

BANA e COSTA, C. A.; OLIVEIRA, R. C. Assigning priorities for maintenance, repair and refurbishment in managing a municipal housing sTOCk. European Journal of Operational Research, n.138, p. 380-391, 2002.

BANA e COSTA, C. A. __ Processo de apoio à decisão: problemáticas, actores e acções. Apostila do Curso Metodologias Multicritério de Apoio à Decisão - ENE/UFSC. Florianópolis, ago., 1995a.

BANA e COSTA, C. A.; VANSNICK, J. C. Measuring credibility of compensatory preference statements when trade-offs are interval determined. Apostila do Curso Metodologias Multicritério de Apoio à Decisão - ENE/UFSC. Florianópolis, ago. $1995 \mathrm{c}$.

BANA e COSTA, C.A.; VANSNICK, J. C. A theoretical framework for measuring attractiveness by a categorical based evaluation technique (Macbeth). Apostila do Curso Metodologias Multicritério de Apoio à Decisão - ENE/UFSC. Florianópolis, ago., $1995 \mathrm{~g}$.

BORTOLUZZI, S. C.; VICENTE, E. F. R.; ENSSLIN, S. R.; ENSSLIN. L. Práticas de Avaliação de Desempenho Organizacional em Pequenas e Médias Empresas: Investigação em uma empresa de porte médio do ramo moveleiro. In: 3 Es, IV., 2009, Pernambuco. Anais... Recife, 2009. CD-ROM.

CHECKLAND, P., SCHOLES, J. Soft Systems Methodology in Action: a 30year retrospective. Chichester: John Wiley \& Sons Ltd, 1999.

DUTRA, A. Elaboração de um Sistema de Avaliação de Desempenho dos Recursos Humanos do SEA à Luz da Metodologia Multicritério de Apoio à Decisão. 1998. Dissertação (Mestrado), Programa de Pós-Graduação em Engenharia de Produção, Universidade Federal de Santa Cataria, Florianópolis, 1998.

DUTRA, A. Metodologia para avaliar e aperfeiçoar o desempenho organizacional: incorporando a dimensão integrativa à MCDA construtivista-sistêmicosinergética. 2003. Tese (Doutorado) - Programa de Pós-Graduação em Engenharia de Produção, Universidade Federal de Santa Catarina Florianópolis, 2001. 
DUTRA, A.; ENSSLIN, L.; ENSSLIN, S. MCDA: A constructivist approach to the management of human resources at a governmental agency. International Transactions in Operational Reseach (Intl.Trans.in Op. Res.) IFORS - , 2000.

DRUCKER, P. F. O melhor de Peter Drucker: o homem. São Paulo: Nobel, 2001.

ENSSLIN, L.; ENSSLIN, S. R. Material didático apresentado na Disciplina: Avaliação de Desempenho do Programa de Pós-Graduação em Engenharia de Produção da Universidade Federal de Santa Catarina no primeiro trimestre de 2009, Florianópolis: UFSC, 2009.

ENSSLIN, L.; MONTIBELLER NETO G.; NORONHA S. M. Apoio à Decisão. Florianópolis: Insular; 2001.

ENSSLIN, S. A Incorporação da Perspectiva Sistêmico-Sinergética na Metodologia MCDA Construtivista: uma ilustração de implementação. Tese de Doutorado. Programa de Pós-Graduação em Engenharia de Produção - UFSC. Florianópolis. Brasil, 2002.

KAPLAN, R. S.; NORTON, D. P. A Estratégia em Ação - Balanced Scorecard. 7. ed. Rio de Janeiro: Campus, 1997.

IGARASHI, D. C. C.; ENSSLIN, S. R.; ENSSLIN, L.; PALADINI, E. P. A qualidade do ensino sob o viés da avaliação de um programa de pós-graduação em contabilidade: proposta de estruturação de um modelo híbrido. RAUSP - Revista de Administração da Universidade de São Paulo, v. 43, n. 2, p. 117-137, abr/ maio/Jun 2008.

KEENEY, R. L., Value Focused-Thinking: A Path to Creative Decision-making. Cambridge: Harvard Univ. Press, 1992.

LANDRY, M. A note of the concept of 'problem'. Organization Studies, v. 16, n. 2, p. 315-343, 1995.

MATURANA, H. R.; VARELA, F. Autopoiesis and Cognition: The Realization of the Living. Boston Studies in the Philosophy of Science, Dordrecht: D. Reidel Publishing Company, v. 42, 1997.

ROY, B. Decision science or decision-aid science? European Journal of Operacional Research, v. 8, n. 1, p. 184-203,1993.

ROY, B.; VANDERPOOTEN, D. The European School of MCDA: Emergence, 
Basic Features and Current Works. Journal of Multi-Criteria Decision Analysis, p.22-38, 1996.

RICHARDSON, R. J. Pesquisa Social: Métodos e Técnicas. 3. ed. São Paulo: Atlas, 2008.

SANNEMANN, G. D. R. Uso da metodologia MCDA na avaliação sistêmica das organizações: Um estudo da viabilidade e limitações da aplicação da metodologia neste tipo de avaliação. 2001. Tese (Doutorado) - Programa de PósGraduação em Engenharia de Produção, Universidade Federal de Santa Catarina Florianópolis, 2001.

VINCKE, P. Multicriteria Decision-aid. Chichester: John Wiley e Sons, 1990.

YIN, R. K. Estudo de Caso: planejamento e métodos. 3. ed. Porto Alegre: Bookman, 2005. 
